\title{
ANALYSIS OF RECURRENCES IN 322 TIS, T1, OR T2 GLOTTIC CARCINOMAS TREATED BY CARBON DIOXIDE LASER
}

\author{
Giorgio PERETTI, MD \\ BRESCIA, ITALY \\ ANDREA BOLZONI, MD \\ BRESCIA, ITALY \\ Giovanni Parrinello, PhD \\ BREscia, ITALY
}

\author{
MARIA C. MENSI, MD \\ BRESCIA, ITALY \\ STANLEY M. SHAPSHAY, MD \\ BOSTON, MASSACHUSETTS
}

\author{
Cesare PiazZa, MD \\ BRESCIA, ITALY \\ MANUELA ROSSINI, MD \\ BRESCIA, ITALY \\ ANTONINO R. ANTONELLI, MD \\ BRESCIA, ITALY
}

\begin{abstract}
An endoscopic approach to early glottic carcinoma is considered a sound treatment for both previously untreated lesions and selected recurrent lesions. Between January 1988 and December 2000, we treated 322 patients by CO2 laser at a single institution; 37 had Tis, 191 T1a, 55 T1b, and 39 T2 lesions (mean follow-up, 77 months; range, 6 to 180 months). Kaplan-Meier curves showed a 5 year overall survival rate of $88 \%$, a determinate survival rate of $99 \%$, a disease-free survival rate of $81 \%$, a rate of ultimate local control with laser alone of $91 \%$, and a laryngeal preservation rate of $97 \%$. Univariate and multivariate analysis showed that the only factor that statistically affected endoscopic control was lateral extension of the tumor with involvement of the bottom of the ventricle (hazard risk ratio, 4.0; $95 \%$ confidence interval, 1.71 to 9.35). The 58 recurrences were classified according to their location compared with the site of the primary tumor as follows: 14 in the same area (group A), 27 in adjacent subsites with superficial spreading or multifocal distribution (group B), and 17 in adjacent sites by submucosal diffusion to the visceral spaces, cartilaginous framework, or extralaryngeal tissues (group C). For each group, we analyzed the rate of patients who underwent salvage by endoscopic or open neck procedures and the rate of laryngeal preservation. Recurrences in groups A and B were endoscopically treated in $86 \%$ and $74 \%$ of cases, respectively. By contrast, in group $\mathrm{C}$ no patient was endoscopically cured, and there was a low laryngeal preservation rate $(47 \%)$. The pathways of spread in recurrent carcinoma are therefore the single most important factor in predicting its endoscopic curability.
\end{abstract}

KEY WORDS - carbon dioxide laser, endoscopic surgery, glottic carcinoma, recurrence, rescue treatment.

\section{INTRODUCTION}

Early-stage glottic cancer (Tis, T1, or T2) encompasses a variety of lesions ranging from superficial neoplasia involving a portion of the vocal cord to tumors reaching the supraglottic and/or subglottic regions with vocalis muscle infiltration or deep extension to the visceral compartments (inferior and superior paraglottic, and preepiglottic spaces). ${ }^{1-5}$

In order to appropriately stage these lesions, endoscopic evaluation of their superficial extension under microlaryngoscopy combined with tridimensional study by radiologic imaging of the visceral spaces is therefore mandatory. Intraoperative examination with $0^{\circ}, 30^{\circ}, 70^{\circ}$, and $120^{\circ}$ rigid endoscopes allows multiple perspectives of the lesion with an accurate inspection of hidden areas such as the inferior aspect of the vocal cord, the anterior commissure, the bottom and top of the ventricle, and the subglottic region. ${ }^{6}$ Radiologic evaluation by computed tomographic scan and/or magnetic resonance imaging detects the neoplastic extension to the deep visceral spaces, providing information on tumor volume, pathways of intralaryngeal and extralaryngeal spreading, and lymph node status. ${ }^{7}$

Progression of laryngeal cancer is influenced by the presence of well-known anatomic barriers such as the vocal ligament, conus elasticus, ventricular band, quadrangular membrane, and cartilaginous framework delineating the visceral compartments of this organ, in which the tumor usually remains confined. Therefore, the pattern of growth and spreading of the untreated neoplasms is usually predictable on the basis of their origin, localization, and adjacent anatomic structures. ${ }^{1-5}$ By contrast, after surgical excision of the tumor and surrounding healthy tissues, such predictability is considerably decreased, and the endoscopic curability is related to the specific pattern of neoplastic extension through the residual barriers.

We herein present the results of 322 cases of Tis, $\mathrm{T} 1$, or $\mathrm{T} 2$ glottic cancer treated by endoscopic $\mathrm{CO} 2$ laser excision at a single institution. Particular attention is given to the recurrences and to their local path-

From the Department of Otolaryngology (Peretti, Piazza, Bolzoni, Mensi, Rossini, Antonelli) and the Section of Statistics and Biometrics (Parrinello), University of Brescia, Brescia, Italy, and the Department of Otolaryngology-Head and Neck Surgery, Boston University School of Medicine, Boston, Massachusetts (Shapshay).

Presented at the meeting of the American Laryngological Association, Nashville, Tennessee, May 2-3, 2003.

CORRESPONDENCE - Giorgio Peretti, MD, Dept of Otolaryngology, University of Brescia, Piazza Spedali Civili 1, 25123 Brescia, Italy. 
ways of spread into the visceral spaces, in order to clearly delineate the indications, contraindications, and benefits of endoscopic treatment, both as a first therapeutic approach and for salvage surgery.

\section{MATERIALS AND METHODS}

Between January 1988 and December 2000, 322 patients with early-stage glottic squamous cell carcinoma were endoscopically treated by $\mathrm{CO} 2$ laser at the Department of Otolaryngology of the University of Brescia, Italy. These were classified according to the 2002 Union Internationale Contre le Cancer TNM system $^{8}$ and included 37 Tis, $246 \mathrm{~T} 1$ (191 T1a, 55 $\mathrm{T} 1 \mathrm{~b}$ ), and $39 \mathrm{~T} 2$ lesions. Among the T2 lesions, we distinguished 24 lesions with a superficial extension to the supraglottis and/or subglottis but normal vocal cord mobility, and 15 tumors with impaired mobility. The patient population included 304 men and 18 women with a mean age of 61 years (range, 29 to 88 years). With the exception of 90 patients who had undergone random biopsy or mucosal stripping for diagnostic purposes elsewhere and were therefore enrolled at our institution for subsequent endoscopic treatment of persistent glottic erythroleukoplakias, none of the other patients had been previously treated.

Tumor excision under microlaryngoscopy was always performed with a Sharplan 1055 S CO2 laser (Sharplan, Tel Aviv, Israel) with superpulse delivery in continuous mode ( 1 to $5 \mathrm{~W}$ ), coupled with an Acuspot 712 micromanipulator ( $270-\mu \mathrm{m}$ spot size).

The endoscopic resections were graded according to the European Laryngological Society Classification, including 5 types of cordectomy: subepithelial (type I), subligamental (type II), transmuscular (type III), total (type IV), and extended (type V). ${ }^{9}$ Their choice was based on the superficial and deep extension of the tumor, which was evaluated before and during operation by means of videolaryngostroboscopy, rigid endoscopy, supravital staining, and infusion of saline solution into Reinke's space. In selected patients with $\mathrm{T} 1 \mathrm{~b}$ lesions involving the anterior commissure or $\mathrm{T} 2$ lesions, a preoperative computed tomographic scan or magnetic resonance imaging scan was performed to rule out any infiltration of the cartilaginous framework and to precisely evaluate the paraglottic and preepiglottic extension.

On the basis of the aforementioned diagnostic workup, we performed a type I cordectomy in 22 lesions assumed to be carcinomas in situ that did not transgress the basal membrane; a type II cordectomy in 62 lesions of the middle third of the vocal cord suspected to be microinvasive or invasive carcinomas; a type III resection in 90 patients previously submitted elsewhere to random biopsies, mucosal stripping, or inadequate surgical procedures with alteration of the multilayered structure of the vocal cord and persistent erythroleukoplakias; a type IV excision in $53 \mathrm{~T} 1 \mathrm{a}$ lesions involving the entire vocal cord; and a type $V$ cordectomy in 95 cases of tumors extending to the anterior commissure, contralateral vocal cord, supraglottis, or subglottis.

Patients who underwent type I, II, or III cordectomy were treated according to the excisional biopsy technique, with a one-piece removal of the lesion along with a rim of surrounding healthy tissue. By contrast, lesions to be managed by a type IV or V resection first underwent an intraoperative biopsy of the most suspicious area of the lesion with subsequent frozen section. In case of confirmation of the neoplastic nature of the lesion, a type IV or V excision was then performed if the patient had given prior consent to a curative endoscopic procedure. By contrast, if the patient preferred other treatment methods discussed with him or her during counseling, the routine diagnostic workup was completed without any further surgical excision. We did not routinely obtain frozen sections in the operating room after laser resection.

All patients were followed up with periodic videolaryngostroboscopic examinations, scheduled every 2 months in the first 2 years and with decreasing frequency afterward. A second laser procedure was always scheduled within the first 6 months in case of positive surgical margins or the presence of suspicious persistent lesions at subsequent endoscopic follow-up examinations.

All patients of the present series had at least 2 years of follow-up (last consultation on December 2002). The mean follow-up was 77 months (range, 6 to 180 months). Ten patients with less than 2 years of followup (range, 6 to 21 months) died of unrelated causes, and only 1 died of primary and nodal recurrence 17 months after surgery.

Statistical analysis was performed with the SPSS statistical package. Absolute survival data were assessed from the date of surgery to the date of death (regardless of the cause), or the date of last consultation. For the analysis of disease-specific survival data, patients who died of unrelated causes were considered as without recurrence at the date of death. The end point for disease-free survival was the date of local or regional recurrence or of distant metastasis. The end point for local control by endoscopic excision alone was the date of local recurrence requiring open neck surgery and/or radiotherapy. The end point for the laryngeal preservation curve was the date of total laryngectomy. Survival curves were estimated by the Kaplan-Meier method. 
TABLE 1. LOCAL CONTROL BY ENDOSCOPIC EXCISION (LOG-RANK TEST)

\begin{tabular}{|c|c|c|c|}
\hline Variable & $\begin{array}{c}\text { No. of } \\
\text { Patients }\end{array}$ & $\begin{array}{l}\text { Estimated } \\
\text { 5-Year } \\
\text { Survival } \\
\text { Rate (\%) }\end{array}$ & $p$ \\
\hline pT category & & & $.0001 *$ \\
\hline Tis & 37 & 88.4 & \\
\hline $\mathrm{T} 1$ & 246 & 93.1 & \\
\hline $\mathrm{T} 2$ & 39 & 78.2 & \\
\hline Degree of differentiation & & & .6 \\
\hline Tis-G2 & 295 & 91.1 & \\
\hline G3 & 27 & 87.4 & \\
\hline Lateral extension & & & $.0005^{*}$ \\
\hline None & 241 & 92.1 & \\
\hline $\begin{array}{l}\text { Involvement of floor of } \\
\text { ventricle }\end{array}$ & 57 & 94.6 & \\
\hline $\begin{array}{l}\text { Involvement of roof of } \\
\text { ventricle and/or false vocal } \\
\text { cord }\end{array}$ & 24 & 68.9 & \\
\hline Craniocaudal extension & & & .5 \\
\hline None & 249 & 91.3 & \\
\hline $\begin{array}{l}\text { Involvement of anterior } \\
\text { commissure }\end{array}$ & 58 & 88.3 & \\
\hline $\begin{array}{l}\text { Involvement of subglottis } \\
\text { and/or supracommissural } \\
\text { region }\end{array}$ & 15 & 92.9 & \\
\hline Vocal cord mobility & & & .5 \\
\hline Normal & 307 & 91.1 & \\
\hline Reduced & 15 & 86.7 & \\
\hline Vocalis muscle infiltration & & & .2 \\
\hline No & 292 & 91.7 & \\
\hline Yes & 30 & 82.4 & \\
\hline \multicolumn{3}{|c|}{ Neoplastic involvement of surgical margins } & .3 \\
\hline No & 174 & 88.7 & \\
\hline Yes & 148 & 93.3 & \\
\hline Endoscopic re-treatment & & & .1 \\
\hline No & 274 & 91.9 & \\
\hline Yes & 48 & 84.9 & \\
\hline Type of cordectomy & & & .3 \\
\hline I & 22 & 100.0 & \\
\hline II & 62 & 93.5 & \\
\hline III & 90 & 91.9 & \\
\hline IV & 53 & 88.4 & \\
\hline $\mathrm{V}$ & 95 & 87.5 & \\
\hline *Statistically significant. & & & \\
\hline
\end{tabular}

The prognostic value of nine variables (pT category, lateral extension, craniocaudal extension, degree of differentiation, vocal cord mobility, vocalis muscle infiltration, type of cordectomy, involvement of surgical margins, endoscopic re-treatment) on local control by endoscopic excision alone was tested by univariate analysis with the log-rank test (Table 1).

Variables that directly express the extension of the
TABLE 2. MULTIVARIATE COX MODEL

\begin{tabular}{|c|c|c|c|}
\hline Variable & $\begin{array}{l}\text { Hazard } \\
\text { Risk } \\
\text { Ratio }\end{array}$ & $\begin{array}{l}95 \% \\
\text { Confidence } \\
\text { Interval }\end{array}$ & $p$ \\
\hline $\begin{array}{l}\text { Lateral extension; involvement } \\
\text { of floor of ventricle vs no } \\
\text { lateral extension }\end{array}$ & 0.53 & $0.16-1.81$ & .3 \\
\hline $\begin{array}{l}\text { Lateral extension; involvement } \\
\text { of roof of ventricle and/or } \\
\text { false vocal cord vs no lateral } \\
\text { extension }\end{array}$ & 4.00 & $1.71-9.35$ & $.01 *$ \\
\hline $\begin{array}{l}\text { Craniocaudal extension; } \\
\text { involvement of anterior } \\
\text { commissure vs no cranio- } \\
\text { caudal extension }\end{array}$ & 1.47 & $0.64-3.35$ & .4 \\
\hline $\begin{array}{l}\text { Craniocaudal extension; } \\
\text { involvement of subglottis } \\
\text { and/or supracommissural } \\
\text { regions vs no craniocaudal } \\
\text { extension }\end{array}$ & 0.35 & $0.04-2.92$ & .3 \\
\hline Vocal cord mobility & 0.68 & $0.12-3.82$ & .7 \\
\hline Vocalis muscle infiltration & 1.12 & $0.42-3.89$ & .7 \\
\hline $\begin{array}{l}\text { Neoplastic involvement of } \\
\text { surgical margins }\end{array}$ & 0.60 & $0.28-1.32$ & .21 \\
\hline Endoscopic re-treatment & 1.94 & $0.81-4.66$ & .1 \\
\hline \multicolumn{4}{|c|}{$\begin{array}{l}\text { Six covariates; } \chi^{2}=9.53 \text { with } 2 \text { degrees of freedom; } p<.05 \text {. } \\
* \text { Statistically significant. }\end{array}$} \\
\hline
\end{tabular}

tumor (lateral extension, craniocaudal extension, vocal cord mobility, vocalis muscle infiltration) or that are related to the treatment (involvement of surgical margins, endoscopic re-treatment) were chosen for further multivariate analysis. The Cox regression model was used to assess a combination of variables for predicting local control by endoscopic excision. Model selection to identify the variables was based on the Akaike Information Criterion. For each variable, the Cox regression model assessed the hazard risk ratio for local control by endoscopic surgery alone (Table 2).

Recurrence was defined as a biopsy-proven neoplastic lesion treated less than 60 months earlier. For longer time intervals, we defined the lesion as a second laryngeal tumor, independently of its site of origin. We performed a detailed analysis on the first recurrences, classifying them into three different groups according to their location versus the site of the primary tumor as follows: group A, recurrences in the same area as the first tumor; group B, recurrences in adjacent laryngeal subsites with superficial mucosal spreading or a multifocal pattern of distribution; and group C, recurrences in adjacent subsites through a submucosal pathway toward the deep visceral spaces, cartilaginous framework, or extralaryngeal soft tissues.

\section{RESULTS}

In the present series, 3 patients (1\%) died of laryn- 
geal cancer and $43(13 \%)$ died of unrelated causes. In the unrelated-causes group, 17 died of nonneoplastic diseases and 26 of nonlaryngeal tumors. At the end of follow-up, 260 patients $(81 \%)$ were free of laryngeal disease; $16(6 \%)$ were lost to follow-up. The 5-year overall survival rate for this patient population was $88 \%$. The Kaplan-Meier curves showed a determinate survival rate of $99 \%$, a disease-free survival rate of $81 \%$, a rate of ultimate control with laser alone of $91 \%$, and a laryngeal preservation rate of $97 \%$.

Of the nine variables tested with univariate analysis, pT category $(\mathrm{p}=.0001)$ and lateral extension ( $\mathrm{p}$ $=.0005$ ) showed a significant influence on local control with endoscopic excision alone (Table 1). The model of multivariate Cox analysis on local control with endoscopic excision alone included 6 covariates $\left(\chi^{2}=9.53\right.$ with 2 degrees of freedom; $\left.\mathrm{p}<.05\right)$. A significantly increased risk of recurrence was related only to lateral extension (hazard risk ratio, $4.0 ; 95 \%$ confidence interval, 1.71 to $9.35 ; \mathrm{p}=.01$; Table 2 ).

Forty-eight patients (15\%) were submitted to endoscopic reexcision: 34 for positive surgical margins and 14 for persistence of suspicious lesions at the first postoperative follow-up visit. The second surgical specimen tested positive for persistent neoplasia in 21 cases $(44 \%)$.

Fifty-eight patients $(18 \%)$ presented with a first recurrence after a mean of 20 months (range, 7 to 59 months). Ten of these lesions had been initially staged as Tis, 38 as T1, and 10 as T2. On the basis of the aforementioned classification, the first recurrences were subdivided into 3 groups according to their site and pathway of diffusion: group A (14 patients), group B (27), and group C (17).

In group $A, 12$ patients ( $86 \%$ ) underwent salvage endoscopic surgery alone, and 2 had endoscopic surgery plus radiotherapy. In group B, 20 patients (74\%) were treated with an endoscopic procedure, 4 with endoscopy followed by radiotherapy, 1 with laser surgery plus functional neck dissection and radiotherapy, and 2 with radiotherapy alone. In group $C$, no patients underwent salvage with endoscopic surgery alone, 1 had endoscopic surgery plus radiotherapy, 6 had supracricoid laryngectomy, and 9 had total laryngectomy. One patient refused any additional treatment.

\section{DISCUSSION}

The anatomic compartmentalization of the larynx by means of ligaments and membranes makes oncological endoscopic surgery feasible even with a few millimeters' safe margin. In particular, in Tis and Tla glottic tumors, a diagnostic workup including preop- erative videolaryngostroboscopy and intraoperative rigid endoscopy with infusion of saline solution into Reinke's space can be routinely applied in order to better modulate the ultranarrow-margin cordectomies. ${ }^{10-21}$ A previous study from our institution has shown the accuracy of such a test battery, by which neoplastic deep extension is underestimated only in a small number of cases. ${ }^{22}$

Phonomicrosurgery for Tis or T1 glottic cancer has therefore recently reached a favorable balance between oncological complete resection and functional preservation. This balance was made possible with the introduction of endoscopic partial cordectomy, which tailors the amount of vocal cord resected to the deep extent of the lesion, thus minimizing the disruption of surrounding healthy tissues. ${ }^{9}, 11,17,21,23$ Recent studies, in fact, confirmed that superficial cordectomy sparing the vocalis muscle allows definitive treatment with a high cure rate and a vocal outcome comparable to that of normal subjects. ${ }^{23,24} \mathrm{On}$ the other hand, such a treatment policy causes the risk of positive margins, as has also been demonstrated by our experience. Although fewer than half of the patients who underwent reoperation for positive margins showed cancer in the second surgical specimen, one could argue this is an undue amount of undertreatment. However, a number of factors in the present series can be considered responsible for such a finding: the learning curve of the surgeon over a long span of time, thermal damage of the laser and coarctation of the edge of the specimen during excision and formalin fixation, and false positives on the histopathologic examination. Moreover, use of multiple frozen sections for margin control after excisional biopsy was routinely rejected because of their unreliability and intrinsic discrepancy with the phonomicrosurgical approach to these lesions.

On the other hand, more extensive lesions, such as T1b lesions with anterior commissure involvement and $\mathrm{T} 2$ lesions, must be evaluated with imaging before operation in order to avoid an underestimation of the involvement of the visceral spaces and cartilaginous framework. ${ }^{7,25}$ Furthermore, both endoscopy and imaging are extremely useful in customizing the compartmental resections to the volume of the tumor. Such endoscopic procedures extend resection to the anterior commissure, the bottom of the ventricle, and the false vocal cord, sometimes involving the entire paraglottic space, and allow good oncological results, albeit with a poorer vocal outcome. ${ }^{24-32}$

The oncological soundness of our endoscopic approach to early glottic cancer is demonstrated by the local control and laryngeal preservation rates of the present series, which are comparable to those re- 
ported in the literature for both radiotherapy and open neck surgery. $28,33-36$

The most frequent site of origin of glottic cancer is the free edge of the vocal cord. The tumor has a distinct tendency to remain confined to Reinke's space, superficially involving the anterior commissure and/or the vocal process of the arytenoid. Its deep extension is limited by the vocal ligament, which reduces to a minimum the possibility of thyroarytenoid muscle infiltration. ${ }^{11,37}$

The superficial extension of the tumor to the anterior commissure rarely causes thyroid cartilage infiltration, because of the presence of the solid barrier represented by Broyles' ligament. ${ }^{38-41}$ This anatomic structure, formed by the union of the thyroepiglottic ligament, the vocal ligaments, and the conus elasticus, is composed of dense fibroelastic tissue; it has no glandular structures, blood, or lymphatic vessels. On the other hand, tumors of the anterior commissure with supraglottic and/or subglottic extension present a discrete propensity for extralaryngeal spreading through the thyrohyoid membrane superiorly and the cricothyroid space inferiorly. ${ }^{23}$ In such areas, in fact, glandular and vascular structures are present and become much more frequent in both the cranial and caudal directions. ${ }^{38-41}$ Nevertheless, our statistical analysis clearly demonstrates that the presence of such a superficial supracommissural and/or subcommissural extension does not significantly influence the oncological outcome. Such pathways of spread, in fact, can be detected by an appropriate preoperative radiologic examination combined with detailed intraoperative rigid endoscopy. When doubts still persist, an infrapetiolar exploration as described by Zeitels ${ }^{42}$ may further exclude the presence of laryngeal framework involvement. If one or more of these diagnostic findings suggests cartilaginous infiltration, an endoscopic approach has a high risk of failure and exposes the patient to the persistence of disease in the cervical soft tissues.

Our data showed no significant impact on local control of impaired vocal cord mobility due to pathologically confirmed thyroarytenoid muscle infiltration. In such cases, in fact, a cordectomy extended to the entire paraglottic compartment has been shown to be an oncologically safe procedure.
Lateral extension of glottic neoplasms can involve the bottom of the ventricle, the false vocal cord, and the subglottic region, either superficially or deep to the conus elasticus. In our study, a negative impact was found for the involvement of the bottom of the ventricle and false vocal cord due to the neoplastic infiltration from these areas toward the paraglottic space in a vertical direction. The absence of a welldefined anatomic barrier at this level makes it possible for the tumor to become a transglottic lesion with submucosal extension into the supraglottis and subglottis and further extending into the extralaryngeal tissues. ${ }^{40,43,44}$ These lesions obviously are incurable by endoscopic surgery alone and have a poorer prognosis.

In our experience, recurrences following endoscopic surgery present the same biological behavior as the primary lesions. The superficial ones (groups $A$ and $B$ ) tend to remain confined to the mucosal surface and show a slow spreading to the visceral spaces. By contrast, submucosal recurrences (group C) often find fewer anatomic barriers to their deep infiltration and thus spread unpredictably.

These observations are confirmed by a detailed analysis of the recurrences and methods of rescue treatment in the present patient population. In fact, those recurrences classified into groups A and B were endoscopically salvaged in $86 \%$ and $74 \%$ of cases, respectively. The high rates of endoscopic control demonstrate that these lesions have a rate of local control comparable to that observed in the primary tumor. By contrast, recurrences classified into group $\mathrm{C}$ were never endoscopically rescued, even by a compartmental excision of the paraglottic space. Lateral extension and transglottic involvement were mainly found to be the causes of such therapeutic failure.

In conclusion, both primary and salvage endoscopic treatments have as their main limit the lateral submucosal extension of the so-called transglottic tumors. In such cases, the possibilities of endoscopic control by even a compartmental resection are reduced by the absence of anatomic barriers that limit neoplastic spreading to adjacent visceral spaces. Therefore, in such cases, open neck procedures and/or radiotherapy must be considered an alternative therapeutic option with a higher laryngeal preservation rate.

\section{REFERENCES}

1. Pressman JJ, Simon MB, Monell C. Anatomical studies related to the dissemination of cancer of the larynx. Trans Am Acad Ophthalmol Otolaryngol 1960;64:628-38.

2. Russ JE, Sullivan C, Gallager HS, Jesse RH. Conservation surgery of the larynx: a reappraisal based on whole organ study. Am J Surg 1979;138:588-96.

3. Kirchner JA, Carter D. Intralaryngeal barriers to the spread of cancer. Acta Otolaryngol (Stockh) 1987;103:503-13.

4. Beitler JJ, Mahadevia PS, Silver CE, et al. New barriers to ventricular invasion in paraglottic laryngeal cancer. Cancer 1994; 73:2648-52.

5. Buckley JG, MacLennan K. Cancer spread in the larynx: a pathologic basis for conservation surgery. Head Neck 2000 ; 22:265-74. 
6. Andrea M, Dias O, Santos A. Contact endoscopy during microlaryngeal surgery: a new technique for endoscopic examination of the larynx. Ann Otol Rhinol Laryngol 1995;104:3339.

7. Becker M. Malignant lesions of the larynx and hypopharynx. In: Hermans R, ed. Imaging of the larynx. Berlin, Germany: Springer-Verlag, 2001:57-84.

8. Sobin LH, Wittekind C, eds. Union Internationale Contre le Cancer. TNM classification of malignant tumours. 6th ed. New York, NY: Wiley-Liss, 2002.

9. Remacle M, Eckel HE, Antonelli AR, et al. Endoscopic cordectomy. A proposal for a classification by the Working Committee, European Laryngological Society. Eur Arch Otorhinolaryngol 2000;257:227-31.

10. Shapshay SM, Hybels RL, Bohigian RK. Laser excision of early vocal cord carcinoma: indications, limitations, and precautions. Ann Otol Rhinol Laryngol 1990;99:46-50.

11. Peretti G, Nicolai P, Piazza C, Redaelli de Zinis LO, Valentini S, Antonelli AR. Oncological results of endoscopic resections of Tis and $\mathrm{T} 1$ glottic carcinomas by carbon dioxide laser. Ann Otol Rhinol Laryngol 2001 ; 1 10:820-6.

12. Sessions RB, Miller SD, Martin GF, Solomon BI, Harrison LB, Stackpole S. Videolaryngostroboscopic analysis of minimal glottic cancer. Trans Am Laryngol Assoc 1989:56-9.

13. Zhao RX, Hirano M, Tanaka S, Sato K. Vocal fold epithelial hyperplasia. Vibratory behavior versus extent of lesion. Arch Otolaryngol Head Neck Surg 1991;117:1015-8.

14. Colden D, Zeitels SM, Hillman RE, Jarboe J, Bunting G, Spanou K. Stroboscopic assessment of vocal fold keratosis and glottic cancer. Ann Otol Rhinol Laryngol 2001;110:293-8.

15. Andrea M, Dias $\mathrm{O}$. Atlas of rigid and contact endoscopy in microlaryngeal surgery. Philadelphia, Pa: Lippincott-Raven, 1995.

16. Zeitels SM, Vaughan CW. A submucosal true vocal fold infusion needle. Otolaryngol Head Neck Surg $1991 ; 105: 478-9$.

17. Zeitels SM. Premalignant epithelium and microinvasive cancer of the vocal fold: the evolution of phonomicrosurgical management. Laryngoscope 1995; 105(suppl 67).

18. Hirano M, Hirade Y, Kawasaki H. Vocal function following carbon dioxide laser surgery for glottic carcinoma. Ann Otol Rhinol Laryngol 1985;94:232-5.

19. Koufman JA. The endoscopic management of early squamous carcinoma of the vocal cord with the carbon dioxide surgical laser: clinical experience and a proposed subclassification. Otolaryngol Head Neck Surg 1986;95:531-7.

20. Zeitels SM. Microflap excisional biopsy for atypia and microinvasive glottic cancer. Op Techn Otolaryngol Head Neck Surg 1993;4:218-22.

21. Zeitels SM. Phonomicrosurgical treatment of early glottic cancer and carcinoma in situ. Am J Surg 1996;172:704-9.

22. Peretti G, Piazza C, Berlucchi M, Cappiello J, Giudice M, Nicolai P. Pre- and intraoperative assessment of mid-cord erythroleukoplakias: a prospective study on 52 patients. Eur Arch Otorhinolaryngol 2003;260:525-8.

23. Zeitels SM, Hillman RE, Franco RA, Bunting GW. Voice and treatment outcome from phonosurgical management of early glottic cancer. Ann Otol Rhinol Laryngol Suppl 2002;1 11 (suppl 190):3-20.

24. Peretti G, Piazza C, Balzanelli C, Cantarella G, Nicolai P. Vocal outcome after endoscopic cordectomies for Tis and T 1 glottic carcinomas. Ann Otol Rhinol Laryngol 2003;112:1749.

25. Desloge RB, Zeitels SM. Endolaryngeal microsurgery at the anterior glottal commissure: controversies and observations. Ann Otol Rhinol Laryngol 2000;109:385-92.

26. Steiner W. Results of curative laser microsurgery of laryngeal carcinomas. Am J Otolaryngol 1993;14:116-21.

27. Rudert HH, Werner JA. Endoscopic resections of glottic and supraglottic carcinomas with the $\mathrm{CO} 2$ laser. Eur Arch Otorhinolaryngol 1995;252:146-8.

28. Sittel C, Eckel HE, Eschenburg C. Phonatory results after laser surgery for glottic carcinoma. Otolaryngol Head Neck Surg 1998;119:418-24.

29. Eckel HE, Thumfart W, Jungehulsing M, Sittel C, Stennert $E$. Transoral laser surgery for early glottic carcinoma. Eur Arch Otorhinolaryngol 2000;257:221-6.

30. Peretti G, Nicolai P, Redaelli De Zinis LO, et al. Endoscopic $\mathrm{CO} 2$ laser excision for Tis, $\mathrm{T} 1$, and $\mathrm{T} 2$ glottic carcinomas: cure rate and prognostic factors. Otolaryngol Head Neck Surg 2000;123:124-31.

31. Steiner W, Ambrosch P. Endoscopic laser surgery of the upper aerodigestive tract. With special emphasis on cancer surgery. Stuttgart, Germany: Thieme, 2001.

32. Moreau PR. Treatment of laryngeal carcinomas by laser endoscopic microsurgery. Laryngoscope 2000;110:1000-6.

33. Morris MR, Canonico D, Blank C. A critical review of radiotherapy in the management of $\mathrm{T} 1$ glottic carcinoma. Am J Otolaryngol 1994; 15:276-80.

34. Thomas JV, Olsen KD, Neel HB III, DeSanto LW, Suman VJ. Early glottic carcinoma treated with open laryngeal procedures. Arch Otolaryngol Head Neck Surg 1994;120:264-8.

35. Chevalier D, Laccourreye O, Brasnu D, Laccourreye H, Piquet JJ. Cricohyoidoepiglottopexy for glottic carcinoma with fixation or impaired motion of the true vocal cord: 5-year oncologic results with 112 patients. Ann Otol Rhinol Laryngol 1997; 106:364-9.

36. Bron LP, Soldati D, Zouhair A, et al. Treatment of early stage squamous-cell carcinoma of the glottic larynx: endoscopic surgery or cricohyoidoepiglottopexy versus radiotherapy. Head Neck 2001;23:823-9.

37. Ferlito A, Carbone A, DeSanto LW, et al. "Early" cancer of the larynx: the concept as defined by clinicians, pathologists, and biologists. Ann Otol Rhinol Laryngol 1996;105:245-50.

38. Kirchner JA, Fischer JJ. Anterior commissure cancer a clinical and laboratory study of 39 cases. Can J Otolaryngol 1975;4:637-43.

39. Bagatella F, Bignardi L. Morphological study of the laryngeal anterior commissure with regard to the spread of cancer. Acta Otolaryngol (Stockh) 1981;92:167-71.

40. Kirchner JA. Pathways and pitfalls in partial laryngectomy. Ann Otol Rhinol Laryngol 1984;93:301-5.

41. Rucci L, Gammarota L, Borghi Cirri MB. Carcinoma of the anterior commissure of the larynx: I. Embryological and anatomic considerations. Ann Otol Rhinol Laryngol 1996;105:3038 .

42. Zeitels SM. Infrapetiole exploration of the supraglottis for exposure of the anterior glottal commissure. J Voice 1998;12: 117-22.

43. Kirchner JA, Cornog JL Jr, Holmes RE. Transglottic cancer. Its growth and spread within the larynx. Arch Otolaryngol 1974;99:247-51.

44. Rucci L, Gammarota L, Simonetti L, Borghi Cirri MB. TNM glottic: role of the vocal muscle, arytenoid cartilage, and inferior paraglottic space in impaired vocal cord mobility (T2). An embryological and clinical study. Ann Otol Rhinol Laryngol $1998 ; 107: 1038-45$. 